\title{
Simulation Model Creation for Verifying the Production Capacity of a Production Line and Sizing in-Process Inventory
}

\author{
Peter Trebuna $^{1 *}$, Miriam Pekarcikova' and Marek Kliment ${ }^{1}$ \\ ${ }^{1}$ Technical University of Kosice, Faculty of mechanical engineering, Institute of management, industrial and digital engineering, Park Komenskeho 9, \\ 04001 Kosice, Slovakia
}

\begin{abstract}
The high complexity of logistical systems in connection with the high competitive pressure makes the implementation of efficient processes in companies and supply chains inevitable. Unlike the optimization in which an attempt is made to model a problem directly, analytically or through modelling using heuristic, the simulation tracks another, i.e. intuitive approach. The development of information technology has created the need to apply a comprehensive system of technical data management in industrial practice. It was necessary to increase the efficiency of information sharing within the value-added chain of the company on specific projects. The aim of this paper is to create a model of production disposition with material flow simulation in TX Plant Simulation software environment for verifying the maximal potential capacity of production.
\end{abstract}

Keywords: model, simulation, production, PLM, TX Plant Simulation.

\section{Introduction}

Nowadays, PLM system tools are used in enterprises to maintain and increase competitiveness. This allows collecting all product information and using it to retrieving advantage. Lifecycle management can also be understood as a business strategy that is designed to help innovate, promote, advance and move the product out of the market while supporting the most advanced methods and knowledge throughout the product life cycle.

The importance of digitization, modularity, networking and connectivity in the context of automation allows for better adaptation of future generations of manufacturing networks to an increasingly dynamic market. In order to respond quickly to unexpected events without central replanting, future production systems will have to become more autonomous. Autonomous systems are intelligent machines that perform high-level tasks without detailed programming and without human control. They know their abilities, their status and they can also decide between a set of alternative actions, organize and execute their skills. To be real, autonomous systems will need access to very realistic models of the current state of the process and their own behaviour interacting with their real world environment often referred to as a digital twin. As a consequence of the autonomy, the complexity of ensuring the system's proper behaviour during production is increased so that the desired production goal is achieved. Basically, this can only be achieved by extensive use of model simulation and not only in the design and planning phase, but also during the next stages of the life cycle for purposes such as diagnostics and optimization of operations. [1-7] 
The use of process simulation software helps to design new as well as optimize already established processes. Simulation can increase production flexibility and productivity while reducing production costs. Engineering methods are also used to optimize processes, but they must be well established otherwise they may not bring any improvement or only a very small improvement. By using simulation programs, incorrect implementation of engineering methods can be avoided while their importance also increases in decision-making processes. The simulation model cannot replace detailed planning, therefore needs to be considered as a tool to support this. Considering the entire process from product development to building the productive capacity needed for this product to production and distribution planning can identify many problems in this chain, where the use of discrete event simulation tools is a supportive decision-making tool. [1-7] However, isolated solutions to individual sub-problems only lead to suboptimal results. Therefore, a comprehensive problem-solving concept is needed. Product Lifecycle Management/PLM is a business strategy to create innovation and continuous improvement in research, development, production, planning and product discarding over the product lifecycle. This strategy seeks to gather all process and capitalrelated knowledge with the possibility of re-use and then process this information visually in the field of workflows. [8-13] The visualization carried out affects the subsequent decision-making and the speed of innovation in the companies that use the strategy. [14] One of the many software tools that are part of Siemens PLM software is TX Plant Simulation, whose potential is handled by case study in the article.

\section{Simulation of production processes using the TX Plant Simulation Software}

The use of process simulation software helps to design new as well as optimize already established processes. Simulation can increase production flexibility and productivity while reducing production costs. Simulation is the imitation of a physical thing or process. [1-5] It represents key characteristics and behaviour of a system. Engineering methods are also used to optimize processes, but they must be well established otherwise they may not bring any improvement or only a very small improvement. By using simulation programs, incorrect implementation of engineering methods can be avoided while their importance also increases in decision-making processes. [14-17]

Currently, simulation programsoffertoolstoanalyse and test individual manufacturing, communications, service, logistics, and other processes, resp. systems in the company. By monitoring and evaluating the results of the simulation experiments it is then possible to evaluate e.g. use of machinery and equipment, production line production capacity, detect collision situations, determine optimum storage capacity, and so on. [1,2]

For the solution of the case study was selected product TX Plant Simulation from Siemens. It is a software tool for modeling, simulating and optimizing mainly logistics systems. It is software with hierarchical structure, which is object-oriented, transparent and uses the inheritance of object properties. It allows performing experiments without physical intervention in existing production and provides significant fact-based information. Currently, it is used by successful businesses in various industries. These rely on the power of simulation, because it can easily gain a competitive advantage in the market.

TX Plant Simulation is used to design and optimize production as well as achieve better output results. It points to outputs that are measurable and resultsbased. Plant simulation includes tools such as graphs, statistics, and diagrams to evaluate outputs. Plant Simulation can be used in the following simulations $[1,2,17,18]$ :

1. Simulating assembly, manufacturing processes - it is possible to create a production or assembly model. Subsequently, changes in production are monitored according to set parameters. The great advantage of this system is that it allows you to use drawing documentation.

2. Simulating Logistics Processes - Proper material flow planning is very important. With Plant Simulation it is possible to verify the logistics in the company before real production starts.

3. Simulating human resources - as human labour is also a resource that occurs in a business, it can be simulated. For example, it is possible to simulate device operators.

4. $3 D$ simulation of logistics and production processes - in Plant Simulation it is possible to create 20 models as well as $3 D$ models, which represents a higher simulation model.

In the form of outputs, it is possible to monitor individual process times, the use of machines and also the use of workers. Using simulation, it is possible to experiment and plan without interfering with production and to look for the best solutions. 
Simulation can solve functioning processes, but also create new processes that can be subsequently edited. By using Plant Simulation, it is possible to anticipate the future state of production and design the best strategy that we can optimize. Based on the results and information obtained, it is able to arrive at quick and correct decisions that help to shorten the start-up time to real production.

The benefits of simulation in Plant Simulation include $[1,2,17,18]$ :

$\checkmark$ possibility to test innovative strategies without risk of interference with real production, testing takes place in a virtual environment

$\checkmark$ making full use of production potential

$\checkmark$ optimization of processes, systems and storage

$\checkmark$ reduce the cost of creating new systems by simulation verification

$\checkmark$ use to improve personnel and handling equipment, either to reduce or increase capacity,

$\checkmark$ there is a 20-60\% reduction in stock size depending on the size of the business.

Creating a Production Process Model with TX Plant Simulation includes 4 main phases [1, 2]:

1. Preparation - In preparation we focus on activities such as deciding on the suitability of the simulation, formulation of the task and goal, data definition, data analysis.

\section{(a)}

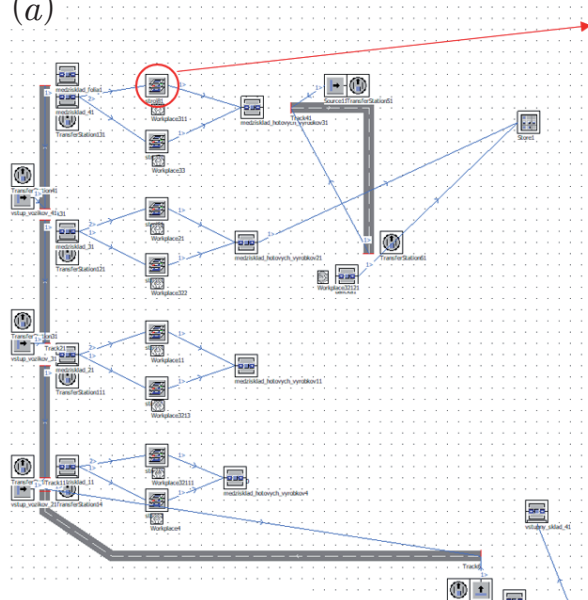

Fig. 1: The product design procedure.
2. Modelling - To create individual parts of a digital business, it is necessary to create a library of so-called digital product designs, tools and machines. Digital products are modelled in $2 D$ and can be created in NX. Later, using any CAD system, it must also be made in $3 D$.

3. Experimentation - To create the required simulation, it is necessary to control and archive the steps and procedures where we can use Teamcenter Manufacturing Process Planer for these activities. It aligns all the information and steps that have been taken throughout the production lifecycle and maps the entire development of production and products. This phase includes activities such as experiment creation, statistical analysis, results interpretation and documentation, design alternatives.

4. Implementation - practical implementation of optimal simulation results.

\section{Results and Discussion}

In the Tx Plant Simulation software environment, a process model based on production disposition and material flow according to production flow in real production were processed. The simulation model concerned the production of products from the paper industry. Specifically, the production flow was processed for two types of products $A$ and $B$, which are produced on the line. The process model of production is in Fig. 1.
The material flow of production process model for product A consists of 3 machines and of 4 machines for product B. Setting up the machines in the material flow reflect the actual disposable capacity of the machine with the consideration of $5 \%$ of waste, i.e., $75 \%$, setting the supply of the semifinished product from the input warehouse through the staff-driven trucks, one truck has a capacity of 1 piece of the input, it is possible to store 4 pieces of

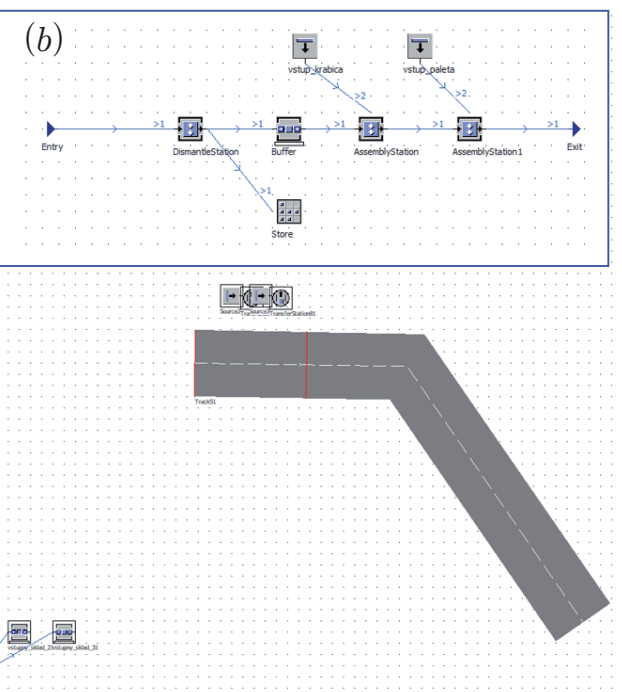

intermediate stocks due to the spatial possibilities. Testing the production capacity potential has been set up for an 8-hour three-shift operation that is used in the company.

Production line from case study was created on principle hierarchical structure. Hierarchical model means inserting individual frames into the other frames. One of the reasons for this way of modelling and testing is a possibility the larger simulation 
model analyses independently. It is possible to create different parts of a simulation model by multiple users. Created sub-frames can be inserted into a main model (also more than once and can be reused in other models). Most important benefit is that the large model thus created is easier to understand and follow a structure reflecting the hierarchy in which it was constructed.

\section{Outputs from simulation run:}

$\checkmark$ process model of the proposed solution, Fig. 1a, process models of individual machines, Fig. $1 \mathrm{~b}$

$\checkmark$ simulation model of the proposed solution, Fig. 2, process models of individual machines, Fig. 3

$\checkmark$ model form running simulation, Fig. 4

\section{$\checkmark$ output statistics:}

- machine usability by production of product A, Tab. 1

- output from 1 machine - product $A$, Tab. 2

- output from 1 machine - product $B$, Tab. 3

$\checkmark$ Annual production of $A$ and $B$ products on 7 machines.
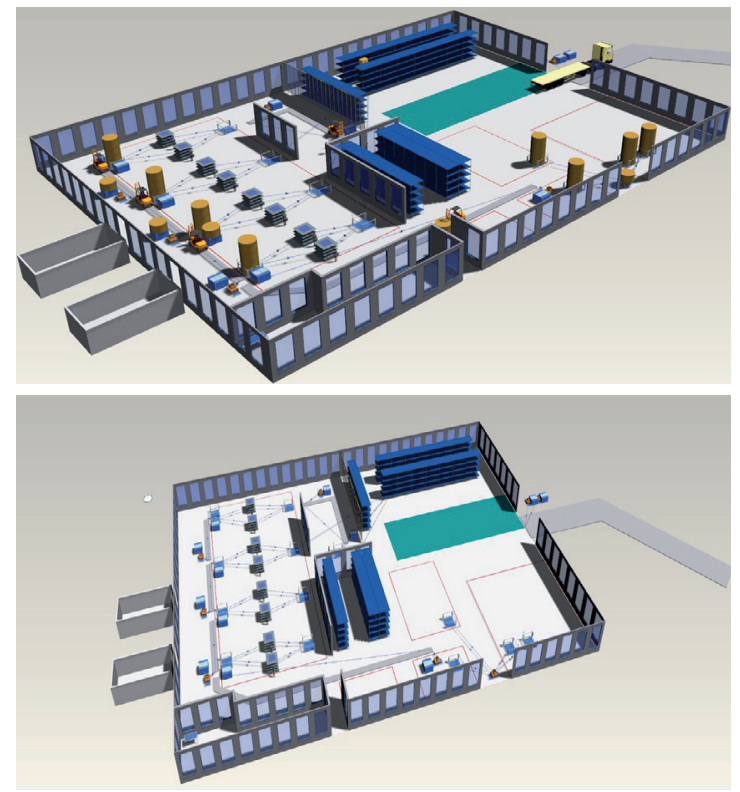

Fig. 2: Production Layout Model in 3D.

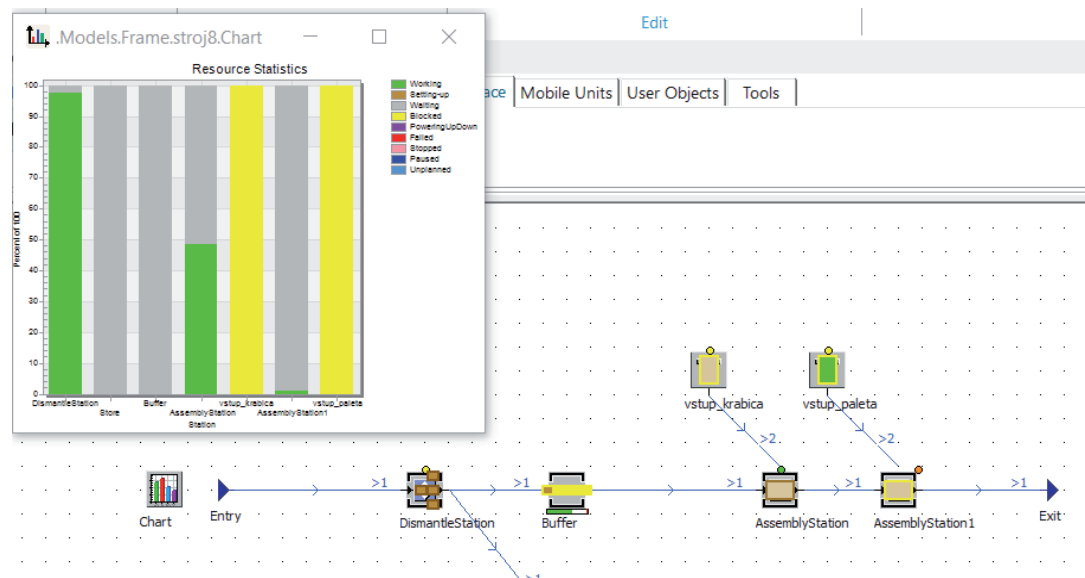

Fig. 3: Process model of selected machine in 2D.

望:

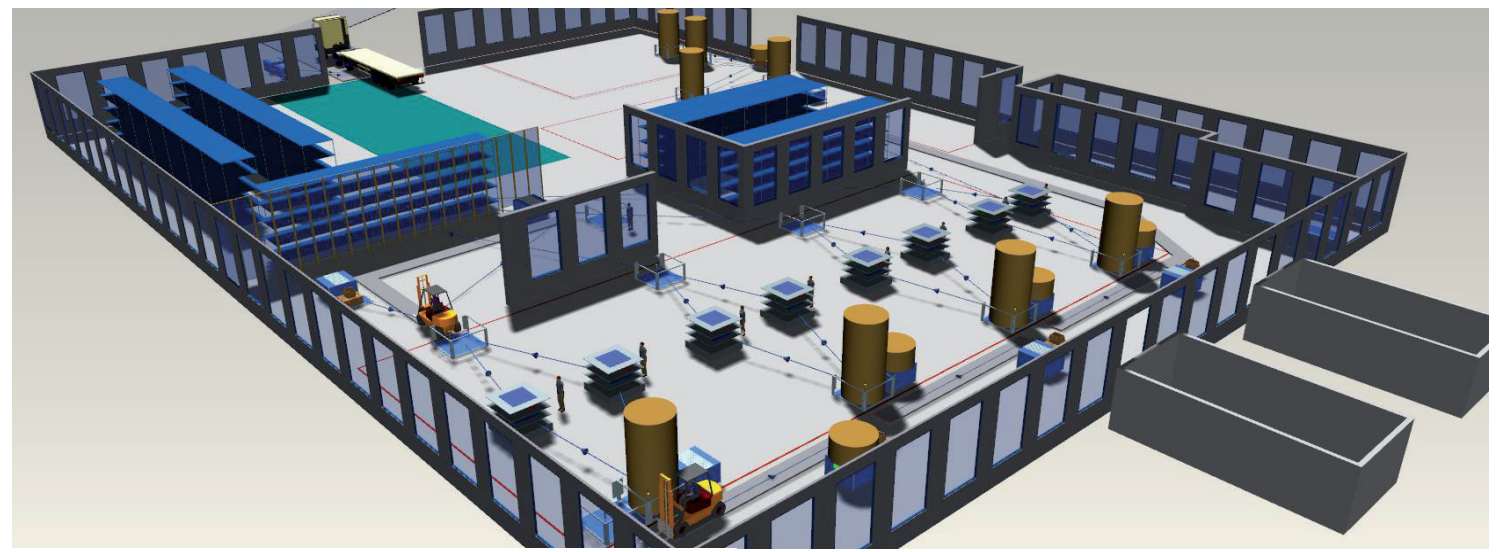

Fig. 3: Model of production disposition in running simulation in 3D. 
Table 1: Usability of selected machine - product A.

\begin{tabular}{|c|c|c|c|c|c|c|c|c|c|c|}
\hline Object & Working & Set-up & Waiting & Blocked & Powering up/down & Failed & Stopped & Paused & Unplanned & Portion \\
\hline Input raw product & $0.00 \%$ & $0.00 \%$ & $0.00 \%$ & $100.00 \%$ & $0.00 \%$ & $0.00 \%$ & $0.00 \%$ & $0.00 \%$ & $0.00 \%$ & 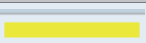 \\
\hline Dismantle Station & $74.96 \%$ & $0.00 \%$ & $0.00 \%$ & $0.00 \%$ & $0.00 \%$ & $25.04 \%$ & $0.00 \%$ & $0.00 \%$ & $0.00 \%$ & n \\
\hline Store & $0.00 \%$ & $0.00 \%$ & $100.00 \%$ & $0.00 \%$ & $0.00 \%$ & $0.00 \%$ & $0.00 \%$ & $0.00 \%$ & $0.00 \%$ & \\
\hline Buffer & $0.00 \%$ & $0.00 \%$ & $100.00 \%$ & $0.00 \%$ & $0.00 \%$ & $0.00 \%$ & $0.00 \%$ & $0.00 \%$ & $0.00 \%$ & 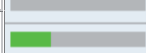 \\
\hline Assembly Station & $32.92 \%$ & $0.00 \%$ & $67.08 \%$ & $0.00 \%$ & $0.00 \%$ & $0.00 \%$ & $0.00 \%$ & $0.00 \%$ & $0.00 \%$ & 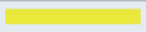 \\
\hline Input box & $0.00 \%$ & $0.00 \%$ & $0.00 \%$ & $100.00 \%$ & $0.00 \%$ & $0.00 \%$ & $0.00 \%$ & $0.00 \%$ & $0.00 \%$ & \\
\hline AssemblyStation1 & $0.63 \%$ & $0.00 \%$ & $99.38 \%$ & $0.00 \%$ & $0.00 \%$ & $0.00 \%$ & $0.00 \%$ & $0.00 \%$ & $0.00 \%$ & \\
\hline Input container & $0.00 \%$ & $0.00 \%$ & $0.00 \%$ & $100.00 \%$ & $0.00 \%$ & $0.00 \%$ & $0.00 \%$ & $0.00 \%$ & $0.00 \%$ & \\
\hline Drain & $0.00 \%$ & $0.00 \%$ & $100.00 \%$ & $0.00 \%$ & $0.00 \%$ & $0.00 \%$ & $0.00 \%$ & $0.00 \%$ & $0.00 \%$ & \\
\hline
\end{tabular}

Table 2: Output of production: 1 machine - product A.

\begin{tabular}{|c|c|c|c|c|c|c|c|}
\hline Object & $\begin{array}{l}\text { Number of } \\
\text { Entries }\end{array}$ & $\begin{array}{l}\text { Number of } \\
\text { Exits }\end{array}$ & $\begin{array}{l}\text { Minimum } \\
\text { Contents }\end{array}$ & $\begin{array}{l}\text { Maximum } \\
\text { Contents }\end{array}$ & $\begin{array}{l}\text { Relative } \\
\text { Empty }\end{array}$ & $\begin{array}{l}\text { Relative } \\
\text { Full }\end{array}$ & $\begin{array}{l}\text { Relative Occupation with } \\
\text { Interruptions }\end{array}$ \\
\hline Input raw product & 8 & 7 & 0 & 1 & $0.00 \%$ & - & $100.00 \%$ \\
\hline Dismantle Station & 7 & 166674 & 0 & 27778 & $0.00 \%$ & - & $100.00 \%$ \\
\hline Store & 8334 & 0 & 0 & 8334 & $14.91 \%$ & - & $4.69 \%$ \\
\hline Buffer & 158340 & 158340 & 0 & 26390 & $67.08 \%$ & $0.00 \%$ & $15.64 \%$ \\
\hline Assembly Station & 159 & 158 & 0 & 1 & $0.00 \%$ & - & $100.00 \%$ \\
\hline Input box & 160 & 159 & 0 & 1 & $0.00 \%$ & - & $100.00 \%$ \\
\hline AssemblyStation 1 & 4 & 3 & 0 & 1 & $0.00 \%$ & - & $100.00 \%$ \\
\hline Input container & 5 & 4 & 0 & 1 & $0.00 \%$ & - & $100.00 \%$ \\
\hline Drain & 3 & 3 & 0 & 1 & $100.00 \%$ & - & $0.00 \%$ \\
\hline
\end{tabular}

Table 3: Output of production: 1 machine - product $B$.

\begin{tabular}{|c|c|c|c|c|c|c|c|}
\hline Object & $\begin{array}{l}\text { Number of } \\
\text { Entries }\end{array}$ & $\begin{array}{l}\text { Number of } \\
\text { Exits }\end{array}$ & $\begin{array}{l}\text { Minimum } \\
\text { Contents }\end{array}$ & $\begin{array}{l}\text { Maximum } \\
\text { Contents }\end{array}$ & $\begin{array}{l}\text { Relative } \\
\text { Empty }\end{array}$ & $\begin{array}{l}\text { Relative } \\
\text { Full }\end{array}$ & $\begin{array}{l}\text { Relative Occupation with } \\
\text { Interruptions }\end{array}$ \\
\hline Input raw product & 7 & 6 & 0 & 1 & $0.00 \%$ & - & $100.00 \%$ \\
\hline Dismantle Station & 6 & 151520 & 0 & 30303 & $0.00 \%$ & - & $100.00 \%$ \\
\hline Store & 7580 & 0 & 0 & 7580 & $17.16 \%$ & - & $0.51 \%$ \\
\hline Buffer & 143940 & 143940 & 0 & 28788 & $70.21 \%$ & $0.00 \%$ & $14.86 \%$ \\
\hline Assembly Station & 144 & 143 & 0 & 1 & $0.00 \%$ & - & $100.00 \%$ \\
\hline Input box & 145 & 144 & 0 & 1 & $0.00 \%$ & - & $100.00 \%$ \\
\hline AssemblyStation1 & 3 & 2 & 0 & 1 & $0.00 \%$ & - & $100.00 \%$ \\
\hline Input container & 4 & 3 & 0 & 1 & $0.00 \%$ & - & $100.00 \%$ \\
\hline Drain & 2 & 2 & 0 & 1 & $100.00 \%$ & - & $0.00 \%$ \\
\hline
\end{tabular}

\section{Conclusions}

Area of the product lifecycle management/ PLM and its data management in development, manufacturing and possible investments makes through modelling and simulation using computer technology very important supportive factor. Creating an optimal PLM solution requires a holistic approach based on a thorough analysis of all activities that need to be performed at all lifecycle levels of the implemented product. Information flows need to be analysed and monitored across the entire organizational structure, both at the level of in-house activities and in business outside of corporate cooperation, whether in the area of component delivery or sales. Such a strategy gives scope for innovation, production, support and decommissioning of products during their life cycle as large corporate corporations as well as smaller company. It serves to preserve best practices, knowledge, processes and intellectual capital for reuse.

\section{Acknowledgments}

This article was created by implementation of the grant project APVV-17-0258 Digital engineering elements application in innovation and optimization of production flows. This publication was supported by the Operational Program Research and Innovation for the project: The Research of New-Generation Materials, Structures, and Technologies in the Industrial Production of the $27^{\text {st }}$ Century, NFP313011T594, co-financed by the European Union from the European Regional Development Fund.

\section{References and Notes}

[1] Bangsaw, S. (2015). Tecnomatix Plant Simulation: Modeling and Programming by Means of Examples, Springer, Switzerland.

[2] Bangsaw, S. (2010). Manufacturing Simulation with Plant simulation and SimTalk: Usage and Programming with Ex- 
amples and Solutions, Springer-Verlag Berlin Heidelberg.

[3] Lehocká, D., Hlavatý, I., Hloch, S. (2016). Rationalization of material flow in production of semitrailer frame for automotive industry. Technical Gazette, Vol. 23, No. 4, 1215-1220, doi:10.17559/TV-20131113100109.

[4] Krajcovic, M., Plinta, D. (2012). Comprehensive approach to the inventory control system improvement. Management and Production Engineering Review, 2012. Vol. 3, Issue 3, ISSN 2082-1344, 34-44.

[5] Centobelli, P., Cerchione, R., Murino, T., Gallo, M. (2016). Layout and material flow optimization in digital factory. International Journal of Simulation Modelling, Vol. 15, No. 2, 223235, doi:10.2507/IJSIMM15(2)3.327.

[6] Badida, M., Gombar, M., Maslejova, A., Sobotova, L., Kmec, J., Vagaska, A. (2015). Evaluation of zinc coating quality by statistical methods. Przemysl Chemiczny. Vol. 94, No. 12, 2146-2149, doi.:10.15199/62.2015.12.11.

[7] Trebuna, P., Markovic, J., Kliment, M., Halcinová, J. (2015). Modeling in Industrial Engineering. TU Kosice, 1st edition, Kosice.

[8] Straka, M. (2010). Alfa, a.s. distribution logistics system. Acta Montanistica Slovaca, Vol. 15, No. 1, 34-43.

[9] Straka, M.; Malindzak, D. (2009). Algorithms of capacity balancing of printing machineries for Alfa Foils, a.s. planning system. Acta Montanistica Slovaca, Vol. 14, No. 1, 98-102.

[10] Rosova, A. (2010). The system of indicators of distribution logistics, transport logistics and material flow as a tool of controlling in logistics enterprise. Acta Montanistica Slovaca, Vol. 15, No. 1, 67-72.

[11] Tecnomatix, from http://www.sova.sk/sk/produkty/tecnomatix, accessed on 16-02-2019.

[12] Lenort, R., Stas, D., Samolejova, A. (2012). Heuristic Algorithm for Planning and Scheduling of Forged Pieces Heat Treatment. Metalurgija, Vol. 51, No. 2, 225-228.

[13] Gregor, M., Hodon, R., Biňasová, V., Dulina, L., Gašo, M. (2018). Design of Simulation-Emulation Logistics System. Modern Machinery Science Journal, 2498-2502, ISSN 18031269.

[14] Ottova, M., Kudrna, J., Poor, P., Edl, M. (2015). New Possibilities of Knowledge Transfer by Playing Manager Games. Procedia - Social And Behavioral Sciences, Vol. 174, 3738-3742, doi: 10.1016/j.sbspro.2015.01.1107.

[15] Gregor, T., Krajcovic, M., Wiecek, D. (2017) Smart Connected Logistics. In Procedia Engineering, Vol. 192, Transcom 2017 12th International Scientific Conference of Young Scientists on Sustainable, Modern and Safe Transport. High Tatras, Grand Hotel Bellevue, Slovakia, 265-270, ISSN 18777058.

[16] Saniuk, S., Samolejova, A., Saniuk, A., Lenort, R.(2015). Benefits and barriers of participation in production networks in a metallurgical cluster - research results. Metalurgija, Vol. 54,
No. 3, 567-570

[17] Klos, S., Patalas-Maliszewska, J. (2013) The impact of ERP on maintenance management. Management and Production Engineering Review, Vol. 4, No. 3, 15-25.

[18] Filo, M., Markovič, J., Kliment, M., Trebuňa, P. (2013) PLM systems and Tecnomatix Plant Simulation, a description of the environment, control elements, creation simulations and models. American Journal of Mechanical Engineering, Vol. 1, No. 7, 165-168. - ISSN 2328-4102

[19] Trebuňa, P., Pekarčíková, M., Kronová, J. (2018) Automation of the casting process by the use of simulation software. Management and Production Engineering Review. Vol. 9, No. 1 82-89, ISSN 2082-1344 